\title{
Extração de DNA e identificação molecular de Olivea neotectonae (T.S. Ramakrishnan \& K. Ramakrishnan) isoladas de folhas de teca (Tectona grandis L.f)
}

\author{
Evelynne Urzêdo Leão ${ }^{\mathrm{a} *}$, , Pedro Raymundo Argüelles Osorio ${ }^{\mathrm{a}}{ }^{\bullet}$, \\ Dalmarcia de Souza Carlos Mourão ${ }^{\mathrm{a}}{ }^{\oplus}$, Gentil Cavalheiro Adorian ${ }^{\mathrm{b}}{ }^{\oplus}$, Gil Rodrigues dos Santos ${ }^{\mathrm{a}}$ \\ a Universidade Federal do Tocantins, Brasil \\ b Centro Universitário Católica do Tocantins, Brasil \\ *Autor correspondente (evelynnegpi@gmail.com)
}

I NFO

Keyworks
forest pathology
rust-causing fungus
Pucciniales
sequencing
ITS region

Palavras-chaves patologia florestal fungo causador de ferrugem

Pucciniales sequenciamento região ITS

\begin{abstract}
A B S T R A C T
DNA extraction and molecular identification of Olivea neotectonae (T.S. Ramakrishnan \& K. Ramakrishnan) isolated from teak leaves (Tectona grandis L.f).

Phytosanitary problems can pose a threat in different crops. And, for this, the first step is to identify and know the main diseases and their impacts on forest stands, such as teak (Tectona grandis L.f). Currently, the rust caused by Olivea neotectonae (T.S. Ramakrishnan \& K. Ramakrishnan) is one of the main fungal diseases that affect the species. The objective of this work was to characterize $O$. neotectonae isolated from teak leaves in the state of Tocantins. The urediniospores of $O$. neotectonae were collected from naturally infected teak leaves in the city of Gurupi-TO. Three different methods were tested, to verify the one that best provided obtaining DNA with sufficient quantity and adequate quality for the correct identification of the pathogen. The method that resulted in the best quantity and quality of DNA from isolates was that described by Alessio and collaborators. The extracted DNA was subjected to amplification of the ITS region and sequenced. The nucleotide sequence of $O$. neotectonae shared a similarity of about $70 \%$ with sequences from the ITS region of other fungi deposited in the GenBank, since until now there are no available sequences of the species $O$. neotectonae.
\end{abstract}

\section{R E S U M O}

Problemas fitossanitários podem representar uma ameaça em diferentes cultivos. E, para isso, o primeiro passo é identificar e conhecer as principais doenças e seus impactos nos povoamentos florestais, como no cultivo da teca (Tectona grandis L.f). Atualmente, a ferrugem causada por Olivea neotectonae (T.S. Ramakrishnan \& K. Ramakrishnan) é uma das principais doenças fúngicas que acometem a espécie. Objetivou-se com este trabalho realizar a caracterização do fungo $O$. neotectonae isolado de folhas de teca no estado do Tocantins, Brasil. Os urediniósporos de O. neotectonae foram coletados em folhas de teca infectados naturalmente, na cidade de Gurupi-TO. Foram testados três diferentes métodos, para verificar o que melhor proporcionasse obtenção de DNA com quantidade suficiente e qualidade adequada para a correta identificação do patógeno. O método que resultou em melhor quantidade e qualidade de DNA de isolados foi o descrito por Alessio e colaboradores. O DNA extraído foi submetido a amplificação da região ITS e sequenciados. A sequência de nucleotídeos de $O$. neotectonae compartilhou uma similaridade de cerca de $70 \%$ com sequências da região ITS de outros fungos depositados no GenBank, visto que até o momento não se encontra sequencias disponíveis da espécie $O$. neotectonae. 


\section{INTRODUÇÃO}

A teca (Tectona grandis L.f, Lamiaceae) é uma espécie florestal exótica originária da Ásia cultivada principalmente para produção de madeira (Figueiredo et al., 2005). A espécie foi introduzida no Brasil no final da década de 60 no estado de Mato Grosso, onde foram estabelecidos os primeiros plantios em escala comercial (Caldeira e Oliveira, 2008). Atualmente, o plantio da espécie encontra-se consolidado no país, principalmente nas regiões Centro-Oeste e Norte, com grande potencial de consumo e de exportação da madeira.

Neste contexto, os problemas fitossanitários podem representar uma ameaça para os produtores florestais, sendo imprescindível a adoção de estratégias para minimizar os riscos de perdas causadas por pragas e doenças, especificamente no cultivo da teca. E, para isso, o primeiro passo é identificar e conhecer as principais doenças e seus impactos nos povoamentos florestais. Atualmente, a ferrugem causada por Olivea neotectonae (=Chaconia tectonae T.S. Ramakrishnan \& K. Ramakrishnan) (Chaconiaceae), a murcha-deceratocystis, causada por Ceratocystis fimbriata (Ceratocystidaceae), a murcha-de-ralstonia, causada por Ralstonia solanacearumi (Burkholderiaceae), e a podridão radicular de causa complexa são consideradas as principais doenças da cultura da teca no Brasil, em função dos prejuízos econômicos que podem gerar caso não haja o manejo adequado (Alfenas, 2017).

A ferrugem causada por $O$. neotectonae é uma doença de fácil visualização, que incide tanto em viveiro quanto em plantios no campo, e está presente em vários estados brasileiros (Bonaldo et al., 2011; Pieri et al., 2011; Gasparotto e Pereira, 2014; Marques et al., 2015). Nas plantas infectadas observam-se manchas de coloração marrom escuro (necróticas) na face adaxial da folha e a presença de pústulas amarelas na face abaxial. No campo, a doença pode ocorrer tanto em plantas jovens quanto em plantas adultas, e o principal prejuízo da doença é a desfolha prematura da planta, que pode reduzir em até $30 \%$ no crescimento (Sales et al., 2017). Recentes estudos e observações em campo indicam a existência de variabilidade para resistência, o que permite a seleção e o plantio de clones resistentes (Alfenas, 2017).

Os fungos causadores de ferrugens são basidiomicetos, pertencentes em geral a ordem Pucciniales (Massola Junior e Krugner, 2011). A classificação destes fungos, entretanto, é ainda um problema devido à morfologia complexa e semelhante entre espécies, ciclo de vida e diferentes hospedeiros. Além disso, a maioria destes organismos atuam como parasitas obrigatórios e não apresentam fase saprofítica em seu ciclo vital
(Alexopoulos et al., 1996; Kimati et al., 2005). Estudos de diversidade e taxonomia de fungos, são tradicionalmente baseados em observações de caracteres morfológicos e taxonômicos, via microscopia de luz e eletrônica, e à identificação por chaves apropriadas (Burgess et al.,1995; MayDe Mio et al., 2006; Castro, 2012). No entanto, apenas com este recurso, já não é mais possível realizar a identificação confiável, a nível de espécie, para a maioria dos gêneros fúngicos (Fungaro, 2000). Sendo assim, o uso de técnicas moleculares para a detecção, identificação e caracterização destes patógenos torna-se essencial, oferecendo maior consistência e confiabilidade à classificação tradicional. Neste sentido, a correta identificação do patógeno consiste no primeiro passo em direção ao manejo adequado da doença por ele causada.

Esse trabalho teve como objetivo realizar a caracterização molecular de $O$. neotectonae isolado de folhas de teca no estado do Tocantins.

\section{MATERIAL E MÉTODOS}

Os urediniósporos de $O$. neotectonae foram coletados em folhas de teca infectados naturalmente no Campus de Gurupi (11 $43^{\circ}$ ' $45^{\prime}$ 'S latitude, $49^{\circ} 04^{\prime} 07^{\prime}$ ' W longitude) na Universidade Federal do Tocantins, com ajuda de um pincel de cerdas macias e armazenados em microtubos até o momento da extração. A área de coleta consistiu em árvores com idade variando de três a sete anos, plantadas no espaçamento de $3,0 \mathrm{~m}$ x $2,0 \mathrm{~m}$. Inicialmente foram testados três diferentes métodos, sendo cada um testado duas vezes, para verificar o que melhor proporcionasse obtenção de DNA com quantidade suficiente e qualidade adequada para a correta identificação do patógeno. Os métodos analisados foram os propostos por Doyle e Doyle (1987), Duan et al. (2003) e Alessio et al. (2013).

No primeiro método (Doyle e Doyle, 1987), os urediniósporos foram macerados em nitrogênio líquido e então submetido à extração do DNA genômico com a utilização do buffer de extração contendo CTAB [20 mM de EDTA, 0,1 M de Tris$\mathrm{HCl} \mathrm{pH} 8,0,1,4 \mathrm{M}$ de $\mathrm{NaCl}, 2 \%$ de CTAB, mais $0,4 \% \beta$-mercaptoethanol], seguindo as demais etapas conforme o protocolo proposto pelos autores.

No método proposto por Duan et al., (2003) modificado por Brammer et al. (2010), os urediniósporos foram colocados em tubos contendo o tampão de extração [ $25 \mathrm{~g} \mathrm{~L}$ de D-Sorbitol, $10 \mathrm{~g} \mathrm{~L}$ de N-Lauroylsarcosine, $0,5 \mathrm{M}$ de $\mathrm{NaCl}, 0,5 \mathrm{M}$ de EDTA e $1 \mathrm{mM}$ de Tris (pH 8)] + Proteinase K (10 
$\mathrm{mg} \mathrm{mL} \mathrm{m}^{-1}$ ), seguido de incubação em banho-maria, e demais etapas do protocolo para a extração do DNA genômico.

No método descrito por Alessio et al. (2013) com algumas modificações, $50 \mathrm{mg}$ de urediniósporos foram suspendidos em $200 \mu \mathrm{L}$ de tampão de extração $[100 \mathrm{mM}$ de Tris- $\mathrm{HCl}(\mathrm{pH} 8,0), 2 \%$ CTAB, $\mathrm{NaCl} 2,2 \mathrm{M}$, EDTA $25 \mathrm{mM}$ e PVP 2,5\%] em um microtubo de $2 \mathrm{ml}$ contendo sete esferas de sílica gel com aproximadamente $3 \mathrm{~mm}$ de diâmetro hidratadas e esterilizadas. Após agitação dos tubos por 5 minutos em aparelho tipo "vortex" para ação de quebra mecânica dos urediniósporos, recuperouse $100 \mu 1$ da suspensão as quais foram adicionados mais $400 \mu \mathrm{L}$ de tampão de extração contendo $5 \mu \mathrm{L}$ de Proteinase $\mathrm{K}\left(10 \mathrm{mg} \mathrm{mL} \mathrm{m}^{-1}\right)$. Os tubos foram incubados em banho-maria por 2 horas a $65^{\circ} \mathrm{C}$ e agitados a cada 20 minutos durante o período. Após a incubação, aos tubos foram adicionados $700 \mu \mathrm{L}$ de clorofórmio:álcool isoamílico (24:1) e invertidos por 5 minutos. Prosseguiu-se com centrifugação por 20 minutos a $15000 \mathrm{~g}$ na temperatura de $4^{\circ} \mathrm{C}$, o sobrenadante foi transferido para novos tubos aos quais se adicionaram $500 \mu \mathrm{L}$ de isopropanol gelado $\left(-20^{\circ} \mathrm{C}\right)$ seguido por leves inversões durante 3 minutos. Os tubos permaneceram em incubação a $-20^{\circ} \mathrm{C}$ por 40 minutos e novamente centrifugados como descrito. Os pellets formados foram lavados duas vezes com etanol $70 \%$, secos a temperatura ambiente por 15 minutos e suspendidos em $50 \mu \mathrm{L}$ de água ultra pura contendo $1 \mu \mathrm{L}$ de RNAse $\left(10 \mathrm{mg} \mathrm{mL}^{-1}\right)$. A extração foi finalizada com incubação a $37^{\circ} \mathrm{C}$ por $1 \mathrm{~h}$. O DNA extraído de cada amostra foi armazenado a $20^{\circ} \mathrm{C}$ até a realização das análises.

As regiões ITS1-5.8S-ITS2 do rDNA de $O$. neotectonae foram amplificadas usando os oligonucleotídeos iniciadores ITS1 (5'TCCGTAGGTGAACCTGCGG-3') e ITS4 (5'TCCTCCGCTTATTGATATGC-3') (White et al., 1990). Para a identificação molecular, $3,0 \mu \mathrm{L}$ das amostras foram submetidos a técnica de PCR (Polymerase Chain Reaction), utilizando 12,5 $\mu \mathrm{L}$ do Kit Taq DNA Polymerase Master Mix Ampliqon III (Ampliqon ApS, Copenhagen, Denmark), $0,25 \mu$ L de cada primer (ITS1 e ITS4) e $9 \mu \mathrm{L}$ de água ultra pura, totalizando o volume de 25 $\mu \mathrm{L}$. As amostras foram testadas em triplicata.

A programação do termociclador (Techne TC5000) consistiu em uma temperatura inicial de 95 ${ }^{\circ} \mathrm{C}$ por 2 min, seguido de 38 ciclos de $95{ }^{\circ} \mathrm{C}$ por 30 segundos (desnaturação), $51{ }^{\circ} \mathrm{C}$ por $1 \mathrm{~min}$ (anelamento), $72{ }^{\circ} \mathrm{C}$ a 1 min (extensão), com uma extensão final de $5 \mathrm{~min}$ a $72^{\circ} \mathrm{C}$. Após a amplificação, $6 \mu \mathrm{L}$ do produto de PCR foram carregados em gel de agarose $0,8 \%$ (TBE 1x) corado com Neotaq Brilliant Green Plus DNA Stain
(Neobio, Brasil) e submetido à eletroforese. A concentração de DNA foi medida em 260 e $280 \mathrm{~nm}$ em espectrofotômetro (Biowave DNA). Os produtos de amplificação foram purificados em PureLink PCR Purification $\mathrm{Kit}^{\circledR}$ (Invitrogen, Carlsbad, CA, EUA), de acordo com as recomendações do fabricante, e encaminhados para sequenciamento direto utilizando o primer ITS1. As sequências foram visualizadas e minimamente editadas por meio do software BioEdit (versão 7.1) e, foram utilizadas para busca de sequências semelhantes no GenBank por meio da ferramenta BLASTn. Filogenias de máxima verossimilhança foram estimadas usando o software MEGA (versão 5.0). A sequência obtida foi depositada no GenBank sob número de acesso KX463504.

\section{RESULTADOS E DISCUSSÃO}

A estrutura da parede celular dos fungos é altamente complexa em comparação com as membranas das células de mamíferos e paredes celulares bacterianas. As características desta parede, como a rigidez, dificultam o processo de rompimento da parede celular, e consequentemente a remoção de proteínas e a precipitação do DNA (Dean et al., 2004).

Neste sentido, a utilização de agentes mecânicos, como a sílica gel utilizada no método descrito por Alessio et al. (2013) facilitou o processo de rompimento da parede celular dos urediniósporos de $O$. neotectonae liberando a molécula de DNA com facilidade. Nos demais métodos testados, o processo de rompimento da parede celular não foi eficiente com a maceração dos urediniósporos.

Estudos moleculares dependem diretamente da qualidade do DNA extraído, portanto, a otimização e estabelecimento de protocolos de extração são necessários, visto que um bom procedimento de extração deve produzir DNA de pureza, qualidade e quantidades adequadas para manipulação (Romano, 1998), além de ser fácil e rápida execução. Além disso, ajustes de protocolo são realizados para que a extração de DNA seja simples, rápida e de baixo custo e obtenha-se DNA de qualidade para análises moleculares (Danner et al., 2011).

Existem diferentes protocolos de extração de DNA disponíveis na literatura, com variações de acordo com a espécie e o tecido a ser utilizado para a extração. Em geral, utiliza-se a maceração do organismo/tecido alvo em nitrogênio líquido para o rompimento da parede celular, um tampão com detergente para o rompimento da membrana celular (com pH 8,0 para impedir a ação das nucleases), reagentes como fenol e/ou clorofórmio para a desnaturação das proteínas, agentes antioxidantes 
para evitar a oxidação de polifenóis e inibição da atividade de peroxidases e polifenoloxidases, proteinase K para facilitar a separação do DNA das proteínas da cromatina, etanol para limpeza e precipitação do DNA e enzima RNAse para digestão e eliminação do RNA (Bonato, 2008).

Muitos protocolos para extração de DNA de fungos utilizam uma variedade de métodos de rompimento da parede celular(Selitrennikoff, 2001). Na literatura são descritos diversos métodos (Raeder e Broda (1985); Zolan e Pukkila (1986); Anikster et al. (1997) e Brake et al. (2001), bem como Kit's comerciais para rápida extração de DNAs fúngicos. Entretanto, estes protocolos não são específicos para a extração de DNA de determinadas espécies. De fato, Manian et al. (2001) apontam não haver um único método de lise celular apropriado para todos os fungos e que cada espécie requer um método específico que seja eficiente para extração de DNA. E conforme Ferreira e Grattapaglia (1998), alterações em protocolos muitas vezes são necessárias devido as diferenças na constituição dos tecidos de cada espécie.

No método proposto por Duan et al., (2003) não foi possível determinar a quantidade de DNA extraída, e a extração pelo método de Doyle e Doyle, 1987 resultou na extração de quantidades insignificantes de DNA, difícil de quantificar. Já o método proposto por Alessio et al (2013), a quantificação do DNA foi significativa, com concentração de DNA variando de 139,9 a 551,7 $\mathrm{mg} \mathrm{mL} \mathrm{m}^{-1}$.

A partir da extração do DNA, a amplificação por PCR da região ITS do rDNA de $O$. neotectonae usando o par de iniciadores ITS1 e ITS4 foi bemsucedida e um fragmento de $600 \mathrm{pb}$ foi obtido (Figura 1). Os resultados obtidos com a PCR estão de acordo com os relatados por outros autores, que encontraram fragmentos em torno de 500 a $800 \mathrm{bp}$ para a região ITS de fungos, dependendo dos pares de primers usados e do isolado analisado (Menezes et al., 2010).
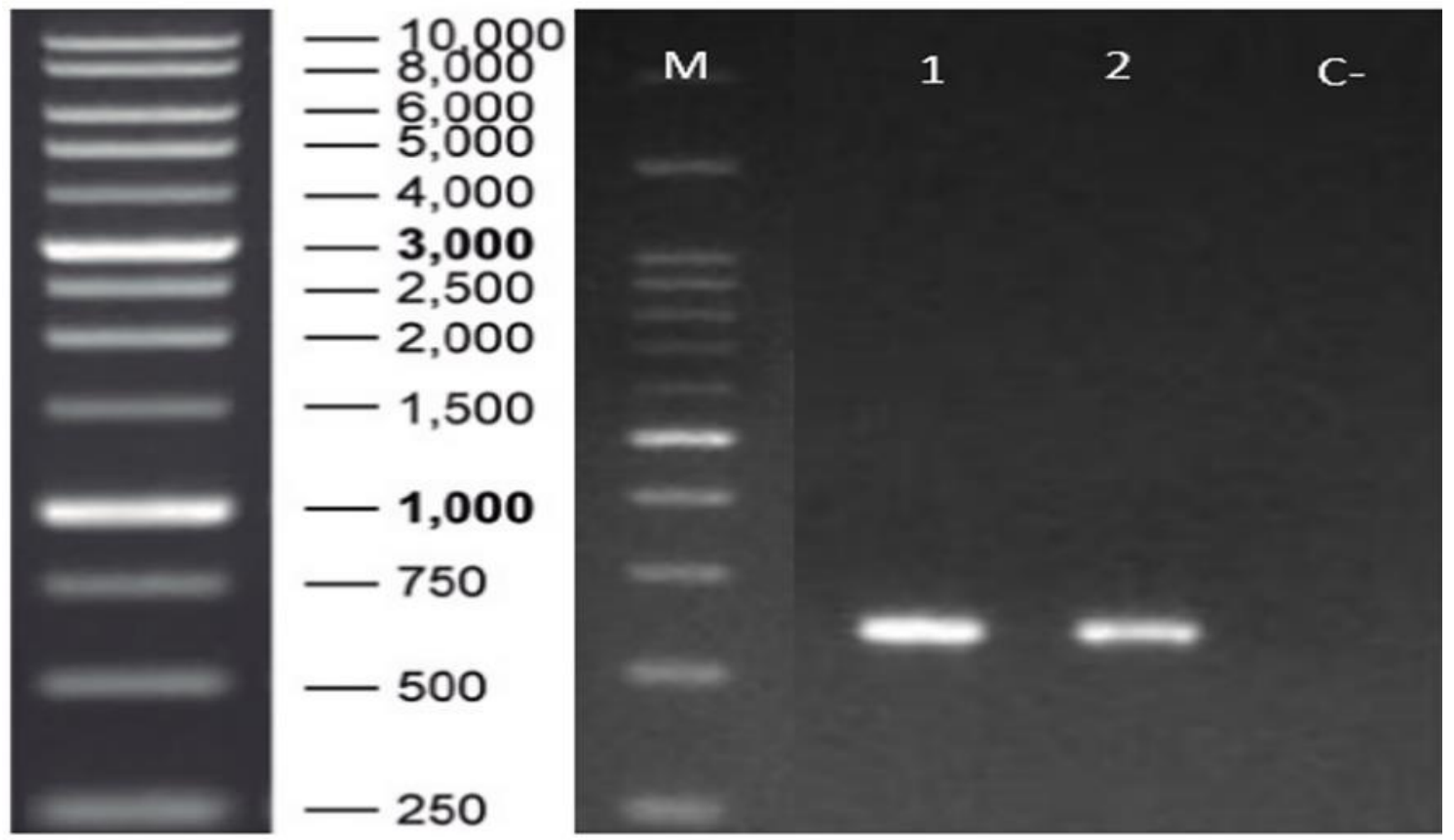

Figura 1 - Eletroforese em gel de agarose $(0,8 \%)$ dos produtos de amplificação da região ITS do rDNA de Olivea neotectonae obtidos usando os primers ITS1 e ITS4. Colunas: M: marcador molecular de $1 \mathrm{~kb}$ (1000 bp); 1-2: amostras; C-: controle negativo.

Nas últimas décadas, verificou-se um aumento significativo no uso de técnicas moleculares para a detecção, identificação e caracterização de fungos por meio de estudos do DNA ribossomal (rDNA). $\mathrm{O}$ fato de as regiões ITS serem relativamente pequenas e aparecerem em grande número de cópias no genoma, permitem que estas sejam amplificadas e sequenciadas com facilidade (Skoube et al., 1999; Leal Junior, 2002).
A região ITS do rDNA de $O$. neotectonae foi sequenciada e depositada no GenBank (número de acesso KX463504). O depósito da sequência poderá auxiliar futuros estudos onde os isolados de $O$. neotectonae possam ser caracterizados com mais precisão, complementando a identificação padrão com base em análises morfológicas. No entanto, uma pesquisa através do BLASTn do GenBank, por sequências ITS semelhantes, revelou que até o 
momento nenhuma outra sequência de nucleotídeos na região ITS de $O$. neotectonae, ou de qualquer outra região deste patógeno, foi depositada no GenBank. A sequência de nucleotídeos de $O$. neotectonae compartilhou uma similaridade de cerca de $70 \%$ com sequências da região ITS de outros fungos depositados no GenBank, indicando alguma homologia com outros fungos.

A árvore filogenética abaixo foi construída com base na sequência gerada a partir da região ITS de rDNA de $O$. neotectonae juntamente com as sequências ITS de nucleotídeos dos patógenos de ferrugem [Austropuccinia psidii (G. Winter) Beenken ] e Maravalia pterocarpi (Thirum.) Thirum, que foram coletadas do GenBank sob os números de acesso KP863477 e KU301795, respectivamente (Figura 2).

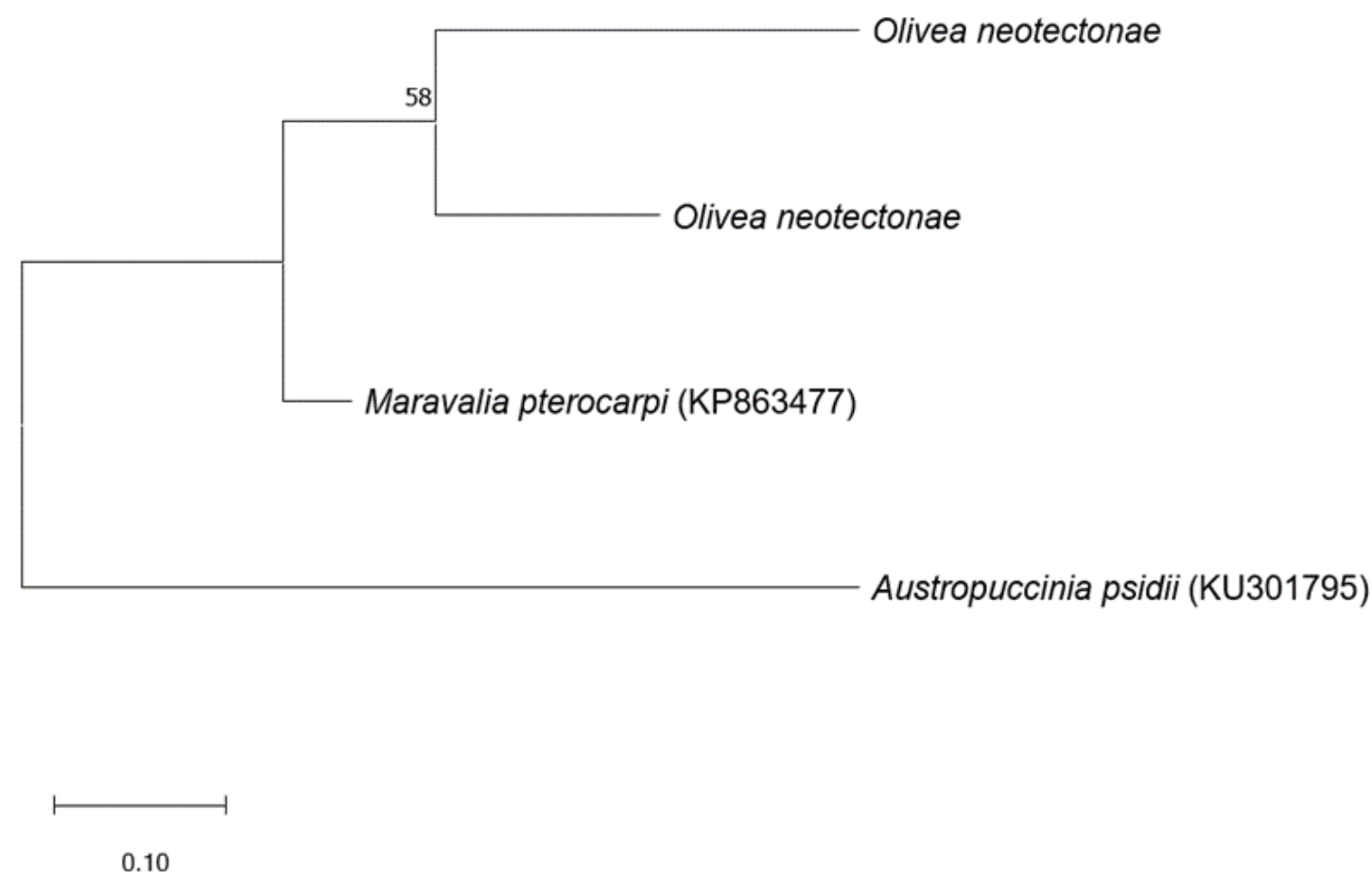

Figura 2 - Árvore filogenética de Olivea neotectonae baseada na região da sequência de rDNA ITS, derivada do Método de Máxima Verossimilhança usando os Parâmetros do Modelo Evolutivo Kimura-2 e teste de bootstrap com 2.000 repetições.

A análise filogenética indicou que os isolados de O. neotectonae obtidos neste estudo são filogeneticamente relacionados ao isolado de $M$. pterocarpi da China, que também é membro da família Chaconiaceae. Em contraste, o isolado de A. psidii na Colômbia encontra-se em um ramo filogeneticamente distante dos isolados de $O$. neotectonae, possivelmente porque $A$. psidii e $O$. neotectonae pertencem a famílias diferentes.

A caracterização realizada neste estudo, utilizando ferramentas moleculares, exerce um papel importante principalmente em estudos filogenéticos de espécies dentro do gênero Olivea, visto que até o momento não existem sequencias disponíveis da espécie $O$. neotectonae.

\section{CONCLUSÕES}

O método de extração do DNA que resultou em melhor quantidade e qualidade de DNA de isolados de $O$. neotectonae foi o descrito por Alessio e colaboradores, onde utilizou-se silica gel para maceração dos urediniósporos.

A sequência de nucleotídeos de $O$. neotectonae compartilhou uma similaridade de cerca de $70 \%$ com sequências da região ITS de outros fungos depositados no GenBank e a arvore filogenética indicou que os isolados de $O$. neotectonae estão relacionadas a outras espécies pertencentes a família Chaconiaceae.

\section{REFERÊNCIAS BIBLIOGRÁFICAS}

Alessio MV, Hoffmann PH, Carneiro, S M. Método rápido para extração de DNA de Puccinia kuehnii. Summa Phytopathologica, v.39, n.3, p.198- 200, 2013. https://doi.org/10.1590/S0100-54052013000300009

Alexopoulos CJ, Mims CW, Blackwell M. Introductory mycology. John Wiley and Sons. New York. 870 p. 1996. 
Alfenas RF. Opiniões - Florestal: celulose, papel, carvão, siderurgia, painéis e madeira. Principais doenças da Teca no Brasil, Ribeirão Preto, p. 14 - 15, 01 fev. 2017.

Anikster Y, Bushnell WR, Roelfs AP, Eilam T, Manisterski J. Puccinia recondita causing leaf rust on cultivated wheats, wild wheats, and rye. Canadian Journal of Botany, Ottawa, v. 75, n. 12, p. 2082-2096, 1997. https://doi.org/10.1139/b97-919

Bonaldo SM, Barceli AC, Trento RA, Gasparotto F, Taffarel C. Relato oficial da ocorrência de Olivea tectonea em teca (Tectona grandis) no Brasil. Summa Phytopatholgica, v.37, n.3, p.153, 2011. https://doi.org/10.1590/S010054052011000300015

Bonato ALV. Extração de DNA genômico de cereais de inverno na Embrapa Trigo. Passo Fundo: Embrapa Trigo, 2008. 11 p. (Embrapa Trigo. Comunicado técnico online, 235).

Brake VM, Irwin JAG, Park RF. Genetic variability in Australian isolates of Puccinia coronata f.sp. avenae assessed with molecular markers and pathogenecity markers. Australian Plant Pathology, Queensland, v. 30, p. 259-266, 2001. https://doi.org/10.1071/AP01039

Brammer SP, Wiethölter P, Chaves MS, Vooss AT. Otimização do método de extração de DNA genômico de Puccinia triticina. Passo Fundo: Embrapa Trigo, 2010. 8 p. html. (Embrapa Trigo. Comunicado técnico online, 287). Disponível em: <http://www.cnpt.embrapa.br/biblio/co/p_co287.htm>.

Burgess T, Malajczuk N, Dell B. Variation in Pisolithus and basidiospore morphology, culture characteristics and analysis of polypeptides using 1D SDS-PAGE. Mycological Research, Edinburg, v.99, n.1, p.1-13, 1995.https://doi.org/10.1016/S0953-7562(09)80309-2

Caldeira SF, Oliveira DLC. Desbaste seletivo em povoamentos de Tectona grandis com diferentes idades. Acta Amazônica, Cuiabá, v.38, n.2, p.223-228, 2008. https://doi.org/10.1590/S0044-59672008000200005

Castro M T D. Pucciniales em plantas nativas do Cerrado brasileiro e em algumas exóticas. Ano de obtenção: 2012. 107 p. Dissertação (Mestrado em Fitopatologia) - Universidade de Brasília, Brasília.

Danner MA, Sasso SAZ, Bittencourt JVM, Citadin I, Sachet MR. Proposta de protocolo para extração de DNA de Jabuticabeira. Ciência Florestal. v.21, p. 363-367, 2011.

Dean TR, Betancourt D, Menetrez MY. A rapid DNA extraction method for PCR identification of fungal indoor air contaminants. Journal of Microbiological Methods. v 56, 431-434p. 2004. https://doi.org/10.1016/j.mimet.2003.11.015.

Doyle JJ, Doyle JL. A rapid DNA isolation procedure for small quantities of fresh leaf tissue. Phytochemistry Bulletin, v. 19, p.11-15. 1987. https://doi.org/10.5902/198050983241

Duan X, Enjalbert J, Vautrin D, Solignac M, Girau, T. Isolation of 12 microsatellite loci, using an enrichment protocol, in the phytopathogenic fungus "Puccinia triticina". Molecular Ecology Notes, Oxford, v. 3, n. 1, p. 65- 67, 2003. https://doi.org/10.1046/j.1471-8286.2003.00350.x
Ferreira ME, Grattapaglia D. Introdução ao uso de marcadores moleculares em análise genética. 3. ed. Brasília, DF: EMBRAPACENARGEN, 220 p. 1998.

Figueiredo EO, Oliveira AD, Scolforo JRS. Análise economia de povoamentos não desbastados de Tectona grandis L.f., na microrregião do Baixo Rio Acre. Cerne, Lavras, v.11, n.4, p.342-353, 2005.

Fungaro MHP. PCR na micologia. Biotecnologia Ciência \& Desenvolvimento, v.3, n.14, p.12- 16. 2000.

Gasparotto L, Pereira JCR. A Ferrugem da Teca no Estado do Amazonas. Embrapa Amazônia Ocidental, Manaus, p.4, 2014. (Comunicado Técnico 101)

Kimati H, Amorim L, Rezende JAM, Bergamin Filho A. Manual de Fitopatologia, vol. 2, doenças das plantas cultivadas $4^{\circ}$ ed. cap. 53, pág 469, São Paulo: Agronômicas Ceres, 2005.

Leal Junior GA. Diagnóstico de Crinipellis perniciosa, em tecidos de Theobroma cacao e caracterização molecular e sorológica de isolados coletados de vários hospedeiros. Ano de Obtenção: 2002. 136p. Dissertação Mestrado. Universidade de São Paulo. Piracicaba Brasil.

Manian S, Sreenivasaprasad S, Mills PR. DNA extraction method for PCR in mycorrhizal fungi. Letters in Applied Microbiology. v 33,307p. 2001. https://doi.org/10.1046/j.1472-765X.2001.01001.x

Marques MLS, Jesus JMI, Virtuoso MCS, Marques VS, Santos GR. Relato de ocorrência da ferrugem da teca, causada por Olivea Neotectonae no estado de Goiás. Revista Verde de Agroecologia e Desenvolvimento Sustentável, Pombal PB - Brasil, v.10, n.5, p.21-25, 2015. https://doi.org/10.18378/rvads.v10i5.3689

Massola Jr NS, Krugner TL. Fungos fitopatogênicos. In: Amorin L, Rezende JAM, Bergamin Filho A. (Ed.). Manual de Fitopatologia: princípios e conceitos. 4 ed. São Paulo: Ceres, 2011. p.149-206.

May De Mio LL, Novaes Q, Alves E. Metodologias de preparação de amostras de ferrugem para estudos morfológicos de urediniósporos por meio de microscopia eletrônica de varredura. Summa Phytopathologica, Botucatu v.32, n.3, p.267-273, 2006. https://doi.org/10.1590/S010054052006000300009

Menezes JP, Lapuatini M, Antoniolli ZI, Blume E, Junges E, Manzoni CG. Variabilidade genética na região its do rDNA de isolados de 63 Trichoderma spp.(Biocontrolador) e Fusarium oxysporum f.sp. chrysanthemi. Ciência e Agrotecnologia, v.34, n,1, p.132-139, 2010. https://doi.org/10.1590/S1413-70542010000100017

Pieri C, Passador MM, Furtado EL, Carvalho Junior AA. Novas observações sobre a ocorrência da ferrugem da teca (Tectona grandis) no Brasil e revisão taxonômica do patógeno. Summa Phytopathologica, Botucatu, v. 37, n.4, p.199-201, 2011. https://doi.org/10.1590/S010054052011000400006

Raeder U, Broda P. Rapid preparation of DNA from filamentous fungi. Letters in Applied Microbiology, v. 1, n. 1, p. 17-20, 1985. https://doi.org/10.1111/j.1472765X.1985.tb01479.x

Romano E. Extração de DNA de Tecidos Vegetais. In: Brasileiro ACM, Carneiro VTC. (Ed). Manual de transformação 
genética de plantas. Brasília. EMBRAPA-SPI/EMBRAPACENARGEN. p.163-177. 1998.

Sales NIS, Leao EU, Correia LCM, Siqueira CA, Santos GR. Temporal progress of teak rust in a tropical area of Tocantins State, Brazil. Acta Amazonica, v.47, n. 3, p. 277-280. 2017. https://doi.org/10.1590/1809-4392201603212

Selitrennikoff CP. Antifungal proteins. Applied and Environmental Microbiology. v 67, p. 2883-2894. 2001. https://doi.org/10.1128/AEM.67.7.

Skoube P, Frisvad JC, Taylor JW, Lauritsen D, Boysen M, Rossen L. Phylogenetic analysis of nucleotide sequences from the ITS region of Penicillium terveticillate species. Mycological Research, Cambridge v.103, p.873-881, 1999. https://doi.org/10.1017/S0953756298007904

White TJ, Bruns T, Lee S, Taylor J. Amplification and direct sequencing of fungal ribosomal RNA genes for phylogenetics. In: Innis MA et al. Comparative evolutionary alnaysis of rDNA ITS regions in Drosopholia. Molecular Biology and Evolution, Oxford, v.11, n.3, p. 513-522, 1990.

Zolan M, Pukkila P. Inheritance of DNA methylation in Coprinus cinereus. Molecular and Cell Biology, Washington, v. 6, p. 195-200, 1986.

https://doi.org/10.1128/mcb.6.1.195 